\title{
Cyclamen coum subsp. coum Miller (Primulaceae/ Çuhaçiçeğigiller) Taksonunun Anatomik, Mikromorfolojik ve Palinolojik Karakterlerinin İncelenmesi
}

\author{
Derviş ÖZTÜRK*10 \\ 1Eskişehir Osmangazi Üniversitesi, Mahmudiye Atçıllk MYO, Bitkisel ve Hayvansal Üretim Bölümü, 26040, \\ Eskişehir, Türkiye
}

(Alınış / Received: 29.11.2019, Kabul / Accepted: 04.05.2020, Online Yayınlanma / Published Online: 20.08.2020)

Anahtar Kelimeler

Anatomi,

Cyclamen coum,

Mikromorfoloji,

Türkiye
Özet: Primulaceae familyasına ait Cyclamen L. cinsinin Türkiye'de 12 taksonu yetişmekte olup, bu türlerin 6'sı endemiktir. Bu araştırma Cyclamen coum subsp. coum Miller taksonunun anatomik, palinolojik ve mikromorfolojik özellikleri belirlenerek Cyclamen L. cinsinin taksonomisine katkı sağlamak amacıyla yapılmıștır. C. coum subsp. coum Miller alt türünün polenlerin tetrakolporat, sferoidal özelliktedir. C. coum subsp. coum Miller' un kök enine, yaprak enine, pedisel ve petiol enine kesitleri ile anatomik çalışmaları ilk kez yapılmıştır. Çalışmada C. coum subsp. coum Miller taksonundan alınan enine ve yüzeysel kesitler sonucunda kök, gövde ve yapraklarda bulunan hücrelerin hem katman sayısı hem de büyüklük bakımından durumları gözlenmiştir. Petiolden alınan enine kesitlerde kollenkimanın varlığı ve iletim demetlerinin ışınsal dağılması ve yaprak yüzeysel kesitlerinde epidermis hücrelerinin poliedrik olması ile karşılaştırılan diğer türlerden ayrılmış̦ır. Mevcut araştırmada elde edilen morfolojik bulgular, genel olarak sayısal verilerde Türkiye Florası'nda verilenlerle tutarlıdır.

\section{Investigation of Anatomical, Micromorphological and Palynological Characteristics of Cyclamen coum subsp. coum Miller (Primulaceae/ Çuhaçiçeğigiller) Taxon}

Keywords

Anatomy,

Cyclamen coum,

Micromorphology,

Turkey

\begin{abstract}
Cyclamen L., the genus of the Primulaceae family has 12 species growing in Turkey, of which 6 are endemic. In this research the anatomical, palinological and micromorphological features of the Cyclamen coum subsp. coum Miller taxon belonging to the genus Cyclamen $\mathrm{L}$. were determined to contribute to the taxonomy of the genus. The pollen of the C. coum subsp. coum Miller species is tetracolporate, spheroidal. Anatomical studies of $C$. coum subsp. coum Miller with root transverse, leaf transverse, pedicel and petiol cross sections were made for the first time. In the study, as a result of transverse and superficial sections taken from $C$. coum subsp. coum Miller taxa, the cells in stem, stem and leaves were observed both in terms of layer number and size. The presence of collenchyma in transient sections from petiole and the diffusion of the conduction bundles and the polyderricity of epidermis cells in leaf superficial sections are different from other species. Morphological findings obtained in the present study was generally consistent with that given in the Flora of Turkey in numerical data.
\end{abstract}

\section{Giriş}

Cyclamen L. cinsi daha önce Myrsinaceae familyası altında sınıflandırılmış, ancak yakın zamanda Primulaceae familyası altında yeniden sınıflandırılmıştır [1]. Cyclamen, doğada doğal olarak bulunan ve bahçelerde yaygın olarak yetiştirilen parlak, petalleri farklı renklerde olan yaklaşık 21 takson çok yıllık bitki türünün bir cinsidir. Bu cinsin üyeleri, yaprak ve çiçeklerinin güzelliğinden dolayı popüler bir süs bitkisidir. Bu amaçla yetiştirilen birçok kültürel form vardır [2, 3]. Ülkemizde doğal olarak yetișen türlerinin bir kısmı süs bitkisi ( $C$. alpinum, C. persicum, C. cilicicum) olarak Avrupa ülkelerine, özellikle de Hollanda'ya ihraç edilmektedir [4-7]. Cyclamen yumruları büyük miktarlarda toksik saponine sahiptir [8]. Bunun yanısıra bu bitkilerden antosiyaninler, terpenler ve 
glikozit bileşenleri de izole edilmiştir [9-11]. Süs bitkilerinde önemli bir yere sahip olduğu gibi, içerdiği bileşiklerden dolayı siklamenler medikal alanda kullanılan bitkiler arasındadır [12]. Yer somunu öncelikle Akdeniz'in etrafına dağılmıştır, ancak Hazar Denizi kıyılarına kadar doğuya doğru uzanır ve Güneybatı Anadolu'da Cyclamen cinsi sıkça "sıklamen, domuzturpu, topalak, yersomunu" olarak bilinir [13].

Cyclamen cinsi, Türkiye'de 12 takson ile temsil edilir ve bunlardan 6'sı (C. repandum Sm-in Sibth. \& Sm., C. parviflorum Pobed, C. pseud-ibericum Hildebr, $C$. trochopteranthum 0. Schwarz, C. cilicicum Boiss \&Heldr., C. mirabile Hildebr.) Anadolu'ya özgüdür [14-18]. Sinıflandırmada Angiosperm Filogeni Grubu III (APG3) sistemi kullanılmıştır. Bu sistem yakın ilişkisi olan büyük taksonomik aralıkları düzenlemektedir. APG3 sistemine göre C. coum subsp. coum Miller taksonu C. coum olarak yayınlanmıştır. 9 Ekim 1991'de Resmi Gazete'de yayınlanarak yürürlüğe giren ve halen yürürlükte olan "Doğal Çiçek Soğanlarının Sökümü, Üretimi ve İhracatına Ait Yönetmelik"' e göre $C$. hederifolium, $C$. coum ve $C$. cilicium bir kota sistemi çerçevesinde doğadan toplanarak ihraç edilmesine izin verilmektedir [1920]. Bilecik il sınırları içerisinde yer alan C. coum subsp. coum Miller lokal olarak bulunmasına rağmen çok nadir ve tehlike altında olan bir tür değildir [14, 21]. Bu çalışmada amacımız bir süs bitkisi olarak kullanılabilecek potansiyele sahip ve üretim çalışmalarının yapılmasına katkısı olacağını düşündüğüm C. coum subsp. coum Miller' un alınan anatomik kesitler ilk kez aslına uygun şekilde kurutmak için kritik noktada kurutularak taramalı elektron mikroskobunda incelenmiștir.

Cyclamen coum Miller, Gard. Dict. ed. 8, no. 6 (1768). Meikle in J. Roy. Hort. Soc. 90:296 (1965). Syn: C. hyemale Salisb., Prodr 118 (1796); C. hiemale Hildbr. In Gartenfl. 33:70 (1904). Ic: Bot. Mag. 1: 4 (1788); J. Roy. Hort. Soc. 90: f. 127 (1965).

\section{Materyal ve Metot}

Araștırma materyali olarak Cyclamen cinsine ait bitki örnekleri çiçeklenme Bozüyük'ten (Bilecik) ve çevresinden toplandı. Örnekler toplanırken her bir bitki örneğinin yumrulu kök, gövde, yaprak ve çiçeğe sahip olmasına dikkat edildi. Toplanan örneklerin morfolojik ölçümleri yapıldıktan sonra bir kısmı herbaryum kurallarına göre kurutularak herbaryum materyali haline getirildi. Eskişehir Osmangazi Üniversitesi herbaryumunda (OUEF:20214, 20215) saklanmaktadır. Cyclamen coum subsp. coum Miller tanımlanması için Türkiye Florası [14, 21] kullanılmıştır.

Arazi çalışması sırasında yapılan gözlemler, toplanan canlı örnekler, herbaryum örnekleri üzerinde yapıldı. Toplanan materyallerin bir kısmı, oda sıcaklığında bir gece etil alkol ve glasiyal asetik asit (3:1) karışımında fikse edildi. Daha sonra materyaller $\% 70$ etil alkol içine alındı. Fikse edilmiş kök enine, gövde enine ve yaprak enine, yaprak alt ve üst kısımlarından el kesiti yöntemi uygulandı. Olympus CX31 ışık mikroskobu ile entellan ile daimi hale getirilen preparatların fotoğrafları görüntülendi.

Taze bitki örneklerinden bazıları morfolojik ölçümler için kullanılmış ve detaylı açıklamaları hazırlandı. Taze bitkiden alınan anatomik kesitler detaylı inceleme için öncelikle Leica EM CPD300 Kritik Nokta Kurutma Cihazı ile kritik noktada kurutuldu ve Hitachi Regulus 8230 marka Alan Emisyonlu Taramalı Elektron Mikroskobu (FE-SEM) ile kesitler fotoğraflandı ve fotoğraflarla desteklenen türler için anatomik açıklamalar hazırlandı.

Palinolojik çalışmada C. coum subsp. coum Miller polenleri FE-SEM ile fotoğraflarl çekildi. Polen numuneleri taze toplanan herbaryum örneklerinden elde edilmiştir. SEM incelemesi için, polen tanecikleri doğrudan çift taraflı karbon bant yapıştırılmış ve Leica EM ACE600 kaplama cihazımız ile altın/ paladyum (Au/Pd)'la kaplanmıştır. Eskişehir Osmangazi Üniversitesi, Merkez Araştırma Laboratuvarı Uygulama ve Araştırma Merkezindeki elektron mikroskobunda numunelerin fotoğrafları çekilmiştir.

Toplandığı lokalite: Quercus cerris L./Saçlımeșe ormanı, 1250 m, 03.04.2019, Camili yayla, Bozüyük, Bilecik.

\section{Bulgular}

Cyclamen cinsi, tuber ve rizomlu çok yllık otsu bir bitkidir. Yapraklar uzun sapl,, tüysüz, ovat, dairemsiye yakın veya böbrek şeklindedir. Tabandaki yapraklar tamamen kalp veya kenarları dişli-lob şeklindedir. Çiçekler tek, koltuklarda ve sarkıktır. Çiçek sapı uzun, çoğunlukla meyvede halkasal şekilde kıvrılmıştır. Çanak yapraklar derince 5 parçalıdır. Taç yapraklar morumsu, pembe veya beyaz, kısa bir yarıküremsi tüp şeklindedir. Çiçeklenmede nadiren yüzeye dik olarak bağlı, taç yaprak parçaları tomurcuk halinde iken burulmuş ve güçlü bir şekilde geriye doğru kıvrıktır. Stamen 5, taç yaprağın tabanından bağlı; filamentleri çok kısa; anterler geniş, meyve durumu birbirine doğru yönelmiş şeklindedir. Ovaryum üst durumlu; stilus zayıf, genellikle anterleri geçmektedir. Kapsül geniş, uçta düzensiz bir yarılmış veya içeri doğru dişler 5 şeklinde kıvrılmıștır. Tohumlar süngersi yapıdadır. (Şekil 1, Tablo 1).

\subsection{Morfolojik Bulgular}

Cyclamen coum subsp. coum Miller, yumrulu çok yıllık otsu bir bitkidir. Yapraklar uzun sapl, tüysüz, ovat, 
Tablo 1. Cyclamen coum subsp. coum Miller taksonunun karşılaştırmalı biometrik ölçümleri

\begin{tabular}{lll}
\hline Morfolojik Karakterler & Meikle, [13] & Tarafımızdan yaplan ölçümler \\
\hline Yumru çapı & $3.5 \mathrm{~cm}$ & \\
\hline Yaprak boyu & $2-5(-7) \mathrm{cm}$ & 4-7cm \\
\hline Yaprak şekli & Yuvarlak veya genișçe kalpsi & Genişçe kalpsi \\
\hline Korolla rengi & $\begin{array}{l}\text { Soluk veya koyu eflatun, nadiren } \\
\text { beyaz }\end{array}$ & Soluk eflatun \\
\hline Koralla boyu & 8-15(-17) mm & $2-4 \mathrm{~cm}$ \\
\hline Korolla şekli & Yumurta şeklinde-yuvarlağa yakın & Yumurta şeklinde \\
\hline
\end{tabular}
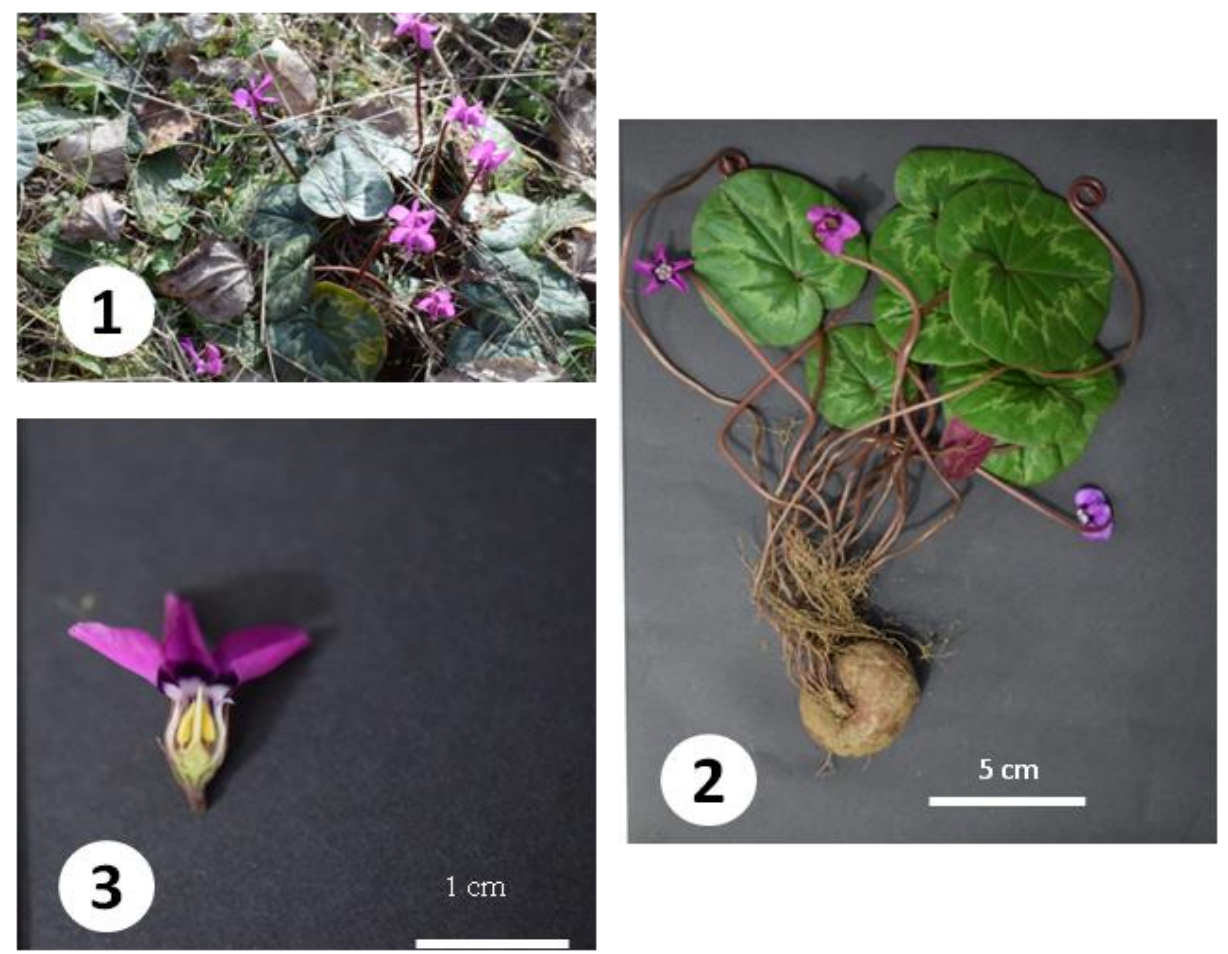

Şekil 1. Cyclamen coum Miller 1. Arazide görünümü, 2. Genel görünümü, 3. Çiçek morfolojisi

dairemsiye yakın șeklindedir. Tabandaki yapraklar tamamen kalp veya kenarları lobudur. Çiçekler tek, çiçek sapı uzun, çanak yapraklar derince 5 parçalıdır. Taç yapraklar eflatun renkli, yarıküremsi tüp şeklindedir. Çiçeklenmede taç yaprak parçaları güçlü bir şekilde geriye doğru kıvrıktır. Stamen 5, taç yaprağın tabanından bağlı; filamentleri kısadır. Ovaryum üst durumlu; stilus zayıf, genellikle anterleri geçmektedir. (Şekil 1, Tablo 1) [17].

\subsection{Anatomik Bulgular}

Kök enine: Epidermis hücreleri tek sıra halinde bulunup, oval veya dikdörtgen şekilli korteks parankiması hücrelerinden meydana gelmiștir. Hücre boyutları 10.24-23.55 x 21.72-30.68 $\mu$ m'dir. Epidermisin altında oval, dikdörtgen şekillere sahip 110-140 $\mu \mathrm{m}$ boyutlarında parankimatik hücrelerden oluşmuş 10-11 sıralı korteks tabakası yer almaktadır. Korteks tabakasının altında tek sira halinde dikdörtgen şekilli 6.20-8.15 x 9.12-10.62 $\mu \mathrm{m}$ boyutlarında endodermis hücreleri bulunmaktadır. Endodermis tabakasının altında tek sıra halinde yassılaşmış perisikl hücreleri yer almaktadır. Perisikl hücrelerinin altında parankimatik hücrelerin arasında küçük boyutlarda floem elemanları yer almaktadır. Merkeze doğru sekonder ksilem ve öze doğru primer ksilem iletim elemanları yer almaktadır. Ksilem elemanları oval şekilli olup 3.21$10.03 \times 2.70-9.35 \mu$ m'dir. Öz bölgesi genellikle oval şekilli parankimatik özelllikteki hücreler bulunmaktadır (Şekil 2, Tablo 2).

Yaprak enine: Cyclamen coum subsp. coum Miller' un yaprak enine kesitinde tek sıra halinde sıralanmış oval ve dikdörtgen şekilli alt ve üst epidermis tabakası bulunmaktadır. Üst epidermis tabakası çoğunlukla dikdörtgen şekilli olup 10.12 - 14.38 (12.25) $\mu \mathrm{m} \times 30.64$ - 40.22 (35.43) um boyutları arasındadır. Palizat ve sünger parankimasının dizilişine göre yaprak bifasiyal tiptedir. Mezofil hücreleri üniform şeklindedir. Vasküler demetler, palizat ile süngerimsi doku arasında uzanır. Vasküler demet tipi kollateraldir. Palizat parankimi hücreleri genellikle 1-2 katmanl, kloroplast açısından zengin ve 40.14 - 60.36 (50.25) $\mu \mathrm{m}$ x 20.15 - 26.55 (23.35) $\mu \mathrm{m}$ boyutta ve süngerimsi parankimi hücreleri 3-5 katmanll, kloroplast bakımından fakir ve 18.20 30.60 (24.40) $\mu \mathrm{m}$ x 20.12 - 30.24 (25.18) um boyutundadır. Stomalar anizositik tiptir (Şekil 3, Tablo 2). 
Tablo 2. Cyclamen coum subsp. coum Miller 'un Anatomisinde Biometrik/Mikrometrik ölçümler

\begin{tabular}{|c|c|c|c|c|c|c|}
\hline \multicolumn{3}{|l|}{ Tür } & \multicolumn{2}{|c|}{ Uzunluk $(\mu \mathrm{m})$} & \multicolumn{2}{|c|}{ Genișlik $(\mu \mathrm{m})$} \\
\hline \multirow{11}{*}{$\begin{array}{l}\text { Cyclamen } \\
\text { coum }\end{array}$} & \multirow{3}{*}{ Kök } & & Min.-Mak. & Ort. & Min.-Mak. & Ort. \\
\hline & & Epidermis & $21.72-30.68$ & 26.2 & $10.24-23.55$ & 16.89 \\
\hline & & Korteks & $9.12-10.62$ & 9.87 & $6.20-8.15$ & 7.17 \\
\hline & \multirow{4}{*}{ Yaprak } & Üst epidermis & $33-55$ & 45.5 & $24-46$ & 35 \\
\hline & & Alt epidermis & $24-40$ & 32 & $20-32$ & 26 \\
\hline & & Palizat P. & $29-70$ & 57.2 & $19-38$ & 29.5 \\
\hline & & Sünger $\mathrm{P}$. & $20-398$ & 30.1 & $58-71$ & 64.5 \\
\hline & \multirow[t]{2}{*}{ Petiol } & Epidermis & $24.16-38.24$ & 36.20 & $20.10-30.60$ & 25.35 \\
\hline & & Korteks & $10.22-42.64$ & 26.43 & $8.20-24.10$ & 16.15 \\
\hline & \multirow{2}{*}{ Pedisel } & Epidermis & $22.28-36.64$ & 29.46 & $16.30-28.44$ & 22.36 \\
\hline & & Korteks & $12.20-40.46$ & 36.33 & $8.40-26.40$ & 17.40 \\
\hline
\end{tabular}
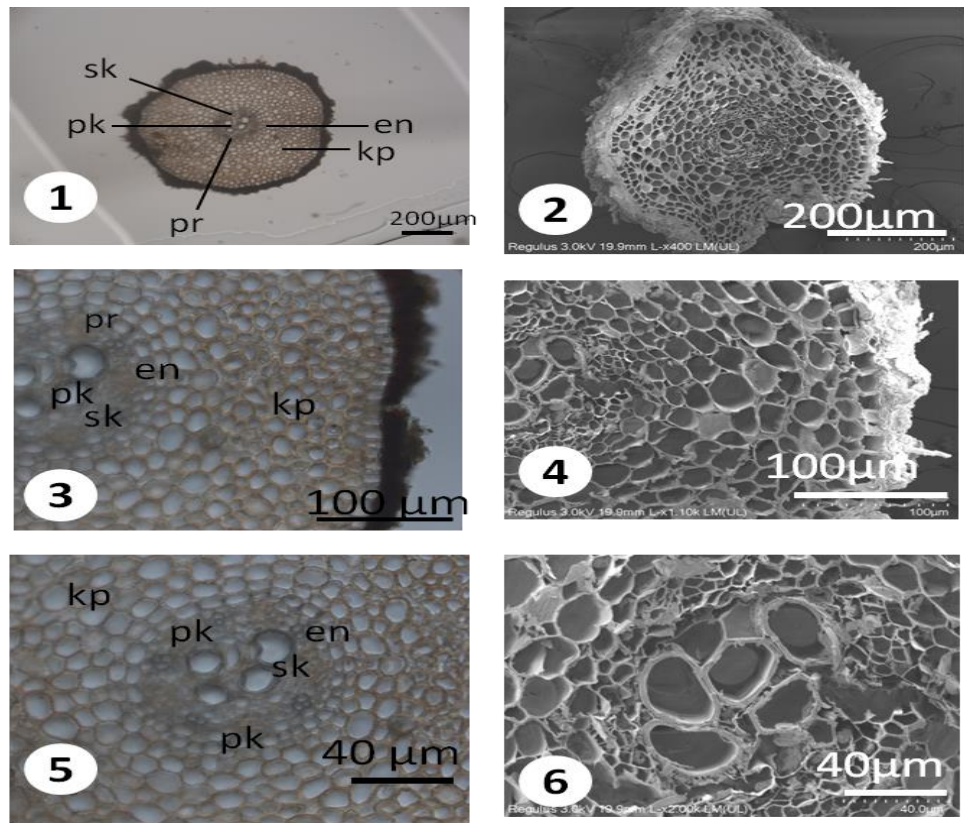

Şekil 2. 1-3-5 Cyclamen coum subsp. coum Miller'un kök enine kesiti (ıșık mikroskobu görüntüsü), 2-4-6 Cyclamen coum Miller kök enine kesiti (taramalı elektron mikroskobu görüntüsü). en:endodermis, pr: perisikl, pe: periderma, pk: primer ksilem, sk: sekonder ksilem, kp:korteks parankiması
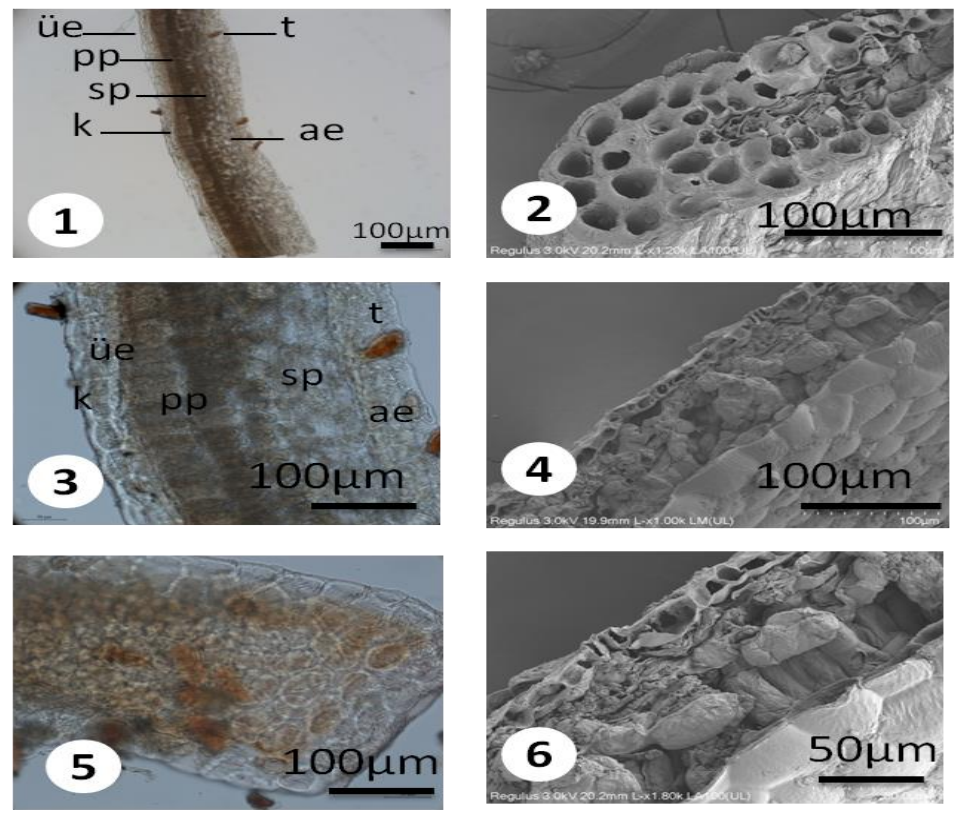

Şekil 3. 1-3-5 Cyclamen coum subsp. coum Miller yaprak enine kesiti (ışık mikroskobu görüntüsü), 2-4-6 Cyclamen coum Miller yaprak enine kesiti (taramalı elektron mikroskobu görüntüsü). t: tüy, k: kutikula, üe: üst epidermis, ae: alt epidermis, pp: palizat parankiması, sp: sünger parankiması. 
Yaprak alt ve üst yüzeysel: Cyclamen coum subsp. coum Mill. yaprak alt ve üst yüzeysel kesitlerde hem üst hem de alt yüzeylerde kalın bir kutikula tabaka ile kaplanmıştır. Her iki epidermal yüzeyde birçok tüy vardır. Üst ve alt epidermisler, düzensiz, büyük, oval ve poliedrik hücreler içerir. Üst epidermisin hücreleri, alt epidermisin hücrelerinden daha büyüktür. Üst epidermal hücre 240-460 (350) $\mu \mathrm{m}$ x 330 - 550 (455) $\mu \mathrm{m}$ boyutunda, alt epidermal hücreler 200-320 (260) $\mu \mathrm{m}$ x 240 - 400 (320) $\mu \mathrm{m}$ boyutlarındadır (Şekil 4, Tablo 2).

Yaprak sapı (petiol) enine: Cyclamen coum subsp. coum Miller yaprak sapı orta kısmından alınan enine kesitlerde yaprak üst yüzeylerde ince bir kutikula tabaka ile kaplıdır. Kutikulalarda çok fazla tek hücreli basit tüyler yer alır. Yaprak sapında epidermis, ince duvarlı oval veya açısal hücrelerle tek katmanl, 20.10 - 30.60 (25.35) $\mu \mathrm{m}$ x 24.16 - 38.24 (36.20) $\mu \mathrm{m}$ boyutlarındadır. Korteks 10-12 katmanlı olup hücreler arası boşlukları olmayan büyük altıgen, oval veya orbiküler hücrelerden, 8.20 - 24.10 (16.15) $\mu \mathrm{m}$ x 10.22 - 42.64 (26.43) $\mu \mathrm{m}$ parankimatik hücrelerden oluşur. İletim demetleri yalnızca bir tanedir ve yaprak sapının merkezinde bulunur. İletim demetlerinin öze doğru ksilem elemanları kortekse doğru ise floem elemanları yer almaktadır. Öz kısım kübik parankimatik hücrelerden oluşmaktadır (Şekil 5, Tablo 2).

Çiçek sapı (pedisel) enine: Cyclamen coum subsp. coum Miller çiçek sapının orta kısmından alınan enine kesitlerde çiçek sapı üst yüzeylerde ince bir kutikula tabaka ile kaplıdır. Kutikulalarda çok fazla tek hücreli basit tüyler yer almaktadır. Çiçek sapında epidermis, ince duvarlı oval veya açısal hücrelerle tek katmanlı, 16.30 - 28.44 (22.36) $\mu \mathrm{m}$ x 22.28 - 36.64 (29.46) $\mu \mathrm{m}$ boyutlarındadır. Epidermisin altındaki hücrelerde yer yer levha kollenkiması çeper kalınlaşmaları bulunmaktadır. Korteks 12-14 katmanlı olup hücreler arası boşlukları olmayan büyük altıgen ve oval, 8.40 26.40 (17.40) $\mu \mathrm{m}$ x 12.20 - 40.46 (36.33) $\mu \mathrm{m}$ parankimatik hücrelerden oluşur. İletim demetleri 78 tane olup üçgen yapıda ve yaprak sapının merkezinde bulunur. Öz kısım kübik parankimatik hücrelerden oluşmaktadır (Şekil 5, Tablo 2).
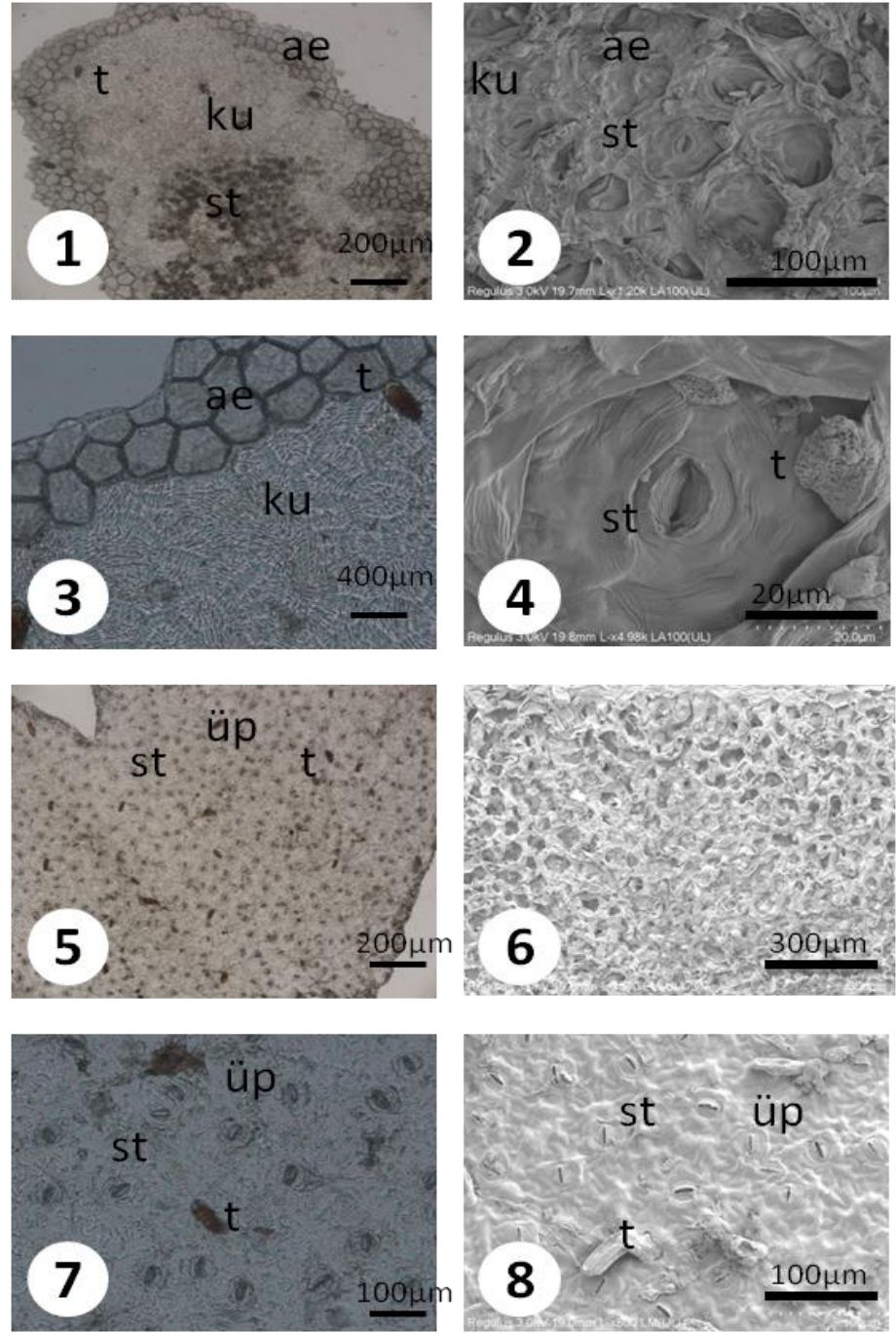

Şekil 4. 1-3 Cyclamen coum subsp. coum Miller yaprak üst yüzelsel kesiti, 5-7 yaprak alt yüzeysel kesiti (1şık mikroskobu görüntüsü), 2-4 Cyclamen coum Miller yaprak alt yüzelsel kesiti, 6-8 yaprak alt yüzeysel kesiti (elektron mikroskobu görüntüsü). t:tüy, ku: kutikula, st: stoma, üp: üst epidermis, ae: alt epidermis 

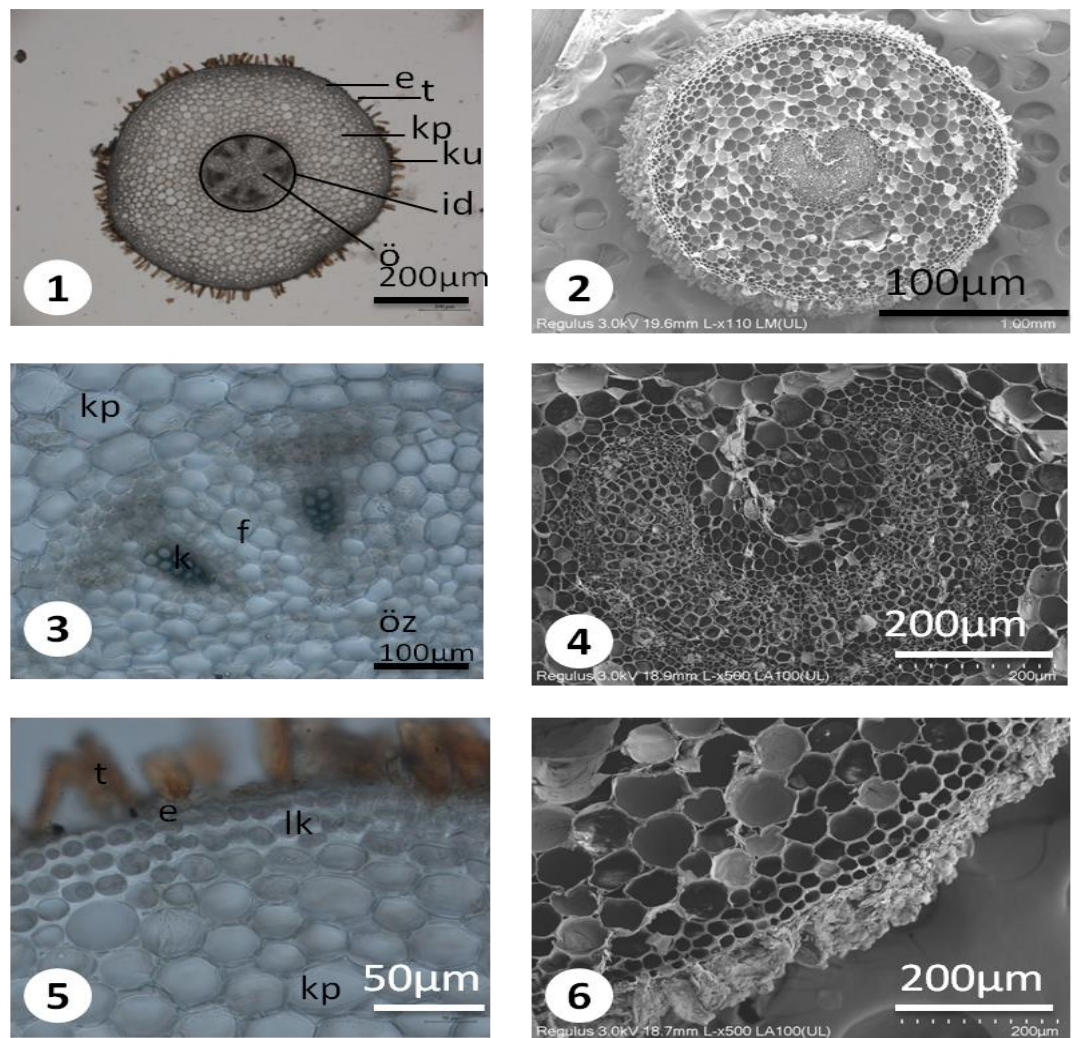

Şekil 5. 1-3-5 Cyclamen coum subsp. coum Miller pedisel enine kesiti (1șlk mikroskobu görüntüsü), 2-4-6 Cyclamen coum Miller petiol enine kesiti (elektron mikroskobu görüntüsü). e: epidermis, t:tüy, ku: kutikula, kp: korteks parankiması, id: iletim demetleri, f: floem, k:ksilem, lk: levha kollenkima, ö: öz.
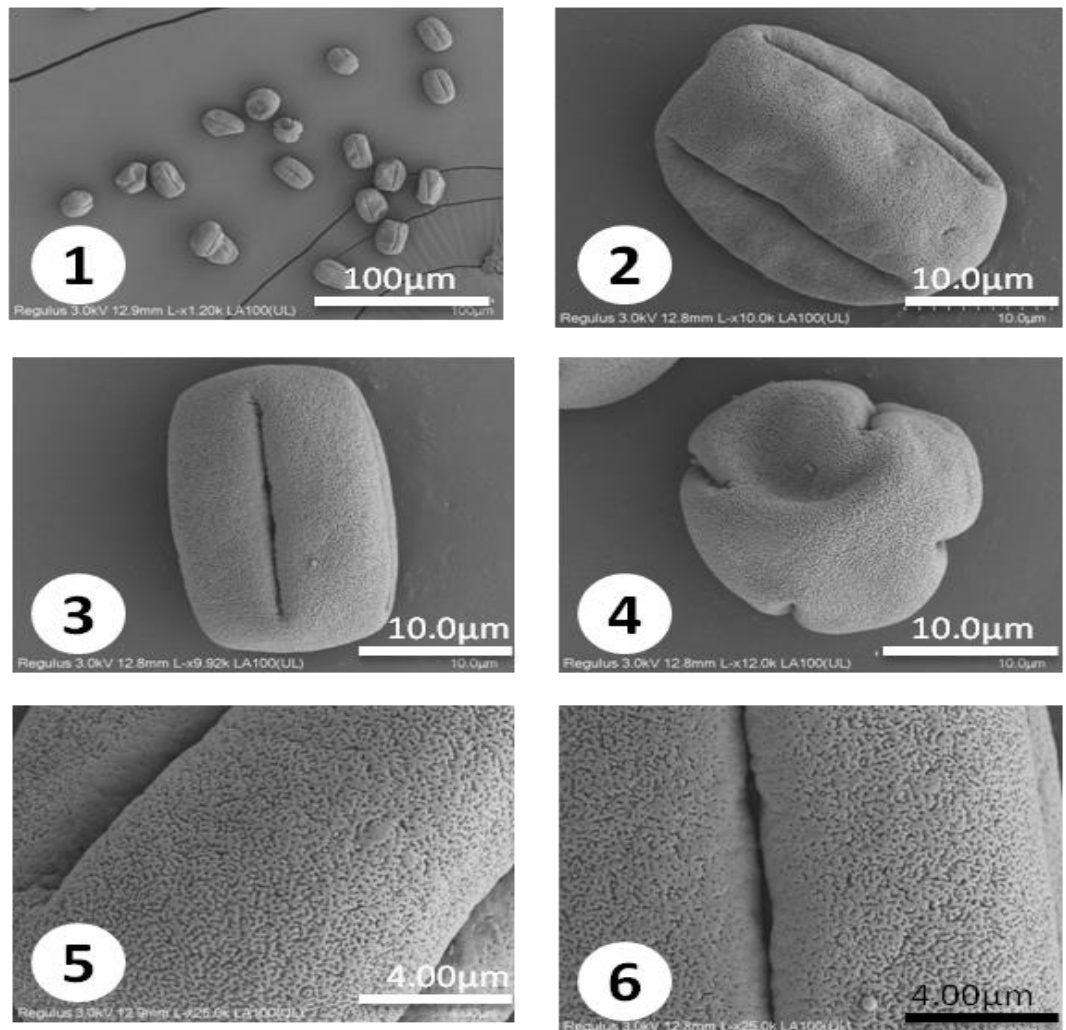

Şekil 6. Cyclamen coum subsp. coum Mill. palinolojik özellikler, 1. Genel görünüș, 2-3 ekvatoral görünüş, 4 polar görünüş, 5-6 ornamentasyon görünüș.

\subsection{Palinolojik Bulgular}

Cyclamen coum subsp. coum Miller polen taneleri tetrakolporat, sferoidaldir (Şekil 6). Polar ekseni (P)
$13.80 \pm 1.20 \mu \mathrm{m}(12.70-15.58 \mu \mathrm{m})$, Ekvatoral ekseni (E) $13.18 \pm 0.72(12.76-15.08 \mu \mathrm{m})$. P / E oranı 1,01' dir. Ekzin $2.502 \mu \mathrm{m}$ kalınlığında mikroretikülat, perforat ve fossulattır [22]. 


\section{Tartışma ve Sonuç}

Bu çalışmada Cyclamen coum subsp. coum Miller' un morfolojik, anatomik ve palinolojik özellikleri araştırılmıştır. Morfolojik çalışmalardan elde edilen sonuçlar, bu türlerin “Türkiye Florası” ndaki bulguları ile karşılaştırılmıştır (Tablo 1), [14]. C. coum subsp. coum Miller' un morfolojik bulgularımız, genel olarak Türkiye Florası'nda [14] verilen verilerle tutarlıdır. Kökün enine kesitinde Çelemli vd. [23] $C$. pseudoibericum Hildebr. türünü incelemiş ve peridermanın çok sıralı olduğunu belirtmişlerdir [23]. Korteks parankimasının altında yer alan tek sıralı endodermis tabakası Mammadov [24] C. mirabile Hildebr. türü ile yaptığı çalışmada kübik hücreler bulunmakta ve çalışmamızla benzerlik gösterirken Çelemli vd. [23] C. pseudoibericum Hildebr. türünde silindirik hücreler yer almaktadır $[3,13]$. Yaprak ve çiçek sapı enine kesitlerinde Çelemli vd. [23], Dusen vd. [25], Özbucak vd. [26] yapılan çalışmalarla benzerlik göstermektedir. Yaprak yüzeysel kesitlerde Çelemli vd. [23] ve Dusen vd. [25] yaptığı çalışmalarda epidermis hücreleri loblu olarak belirtmiştir [23, 25]. Çalışmamızda ise $C$. coum subsp. coum Miller' un epidermis hücrelerinin poliedrik olduğu gözlenmiştir.

Ayrıca, C. coum subsp. coum Miller' un polen taneleri SEM kullanılarak incelenmiş ve Dusen vd. [25] $C$. mirabile Hildebr. türü ile yaptığı çalışmada benzerlik gösterirken, Özbucak vd. [26] yapılan çalışmada polen tanelerinin trikolporat olduğunu belirtmiştir $[23,25]$. C. coum subsp. coum Miller' un polenlerinin taramalı elektron fotoğrafları rapor edilmiștir. Dusen vd. [25] yaptığı çalıșmada kök ve yaprak yüzeysel kesitlerinde kutikula üzerinde salgı tüyü olmayan basit tüyler çalışmamız ile benzerlik göstermektedir [23].

Bu çalışmada, C. coum subsp. coum Miller türüne ait kök, gövde, yaprak ve çiçek sapına ait anatomik özellikleri detaylıca verilmiştir. Yapılan bu çalışmanın, cinse ait yapılacak çalışmalarda yol göstereceği ve bulunan sonuçların cinsin sistematik sonuçlarına katkı sağlayacaktır.

\section{Kaynakça}

[1] Källersjö, M., Gerquist, G., Anderberg A. A. 2000. Generic Realigment in Primuloid Families of the Ericales s.l.: A Phylogenetic Analysis Based on DNA sequences from three chloroplast genes and morphology. American Journal of Botany 87(9), 1325-1341.

[2] Yesson, C., Toomey, N. H., Culham, A. 2009. Cyclamen: time, sea and speciation biogeography using a temporally calibrated phylogeny. Journal of Biogeography 36, 12341252.

[3] Ekim, T., Koyuncu, M., Güner, A., Erik, S., Yıldız, B., Vural, M. 1991. Türkiye'nin ekonomik değer taşıyan geofitleri üzerinde taksonomik ve ekolojik araştırmalar. TC Tarım ve Orman Köyişleri Bakanlığı Orman Genel Müdürlüğü, İşletme ve Pazarlama Dairesi Başkanlığl, 111.

[4] Tanker, M., Tanker, N. 1990. Farmakognozi. Ankara Üniversitesi Eczacılı Fakültesi Yayınlarl, 65(2), 301-302.

[5] Aktan, T., Altan, Y. 2011. Yenisehir (Bursa) Mezarliklarinin Doğal Süs Bitkileri-Ornamental Plants of The Graveyards of Yenisehir (Bursa). Celal Bayar Üniversitesi Fen Bilimleri Dergisi, 7(2), 31-39.

[6] Boztok, Ş. 2002. Siklamen (Cyclamen persicum)'de Çiçeklenme Üzerine Giberelik Asitin Etkisi. Ege Üniversitesi Ziraat Fakültesi Dergisi, 39(3).

[7] Yesson, C., Culham, C. 2006. A phytoclimatic study of Cyclamen. BMC Evolutionary Biology, $6,72,(23)$.

[8] Ishizaka, H., Yamada, H., Sasaki K. 2002. Volatile compounds in the flowers of Cyclamen persicum, C. purpurascens and their hybrids. Scientia horticulturae, 94(1-2), 125135.

[9] Dall'Acqua, S., Castagliuolo, I., Brun, P., Ditadi, F., Palù, G., Innocenti, G. 2010. Triterpene glycosides with in vitro anti-inflammatory activity from Cyclamen repandum tubers. Carbohydrate research, 345(5), 709-714.

[10] Altunkeyik, H., Gülcemal, D., Masullo, M., Alankus-Caliskan, O., Piacente, S., Karayildirim, T. 2012. Triterpene saponins from Cyclamen hederifolium. Phytochemistry, 73, 127-133.

[11] Özhatay, N. 2000. Yabani siklamenler. Sky Life, 1,2 .

[12] Polat, G. 2016. Cyclamen coum Subsp. coum Mill. Taksonunun Bazı Anatomik ve Ekofizyolojik Karakterlerinin Farklı Yükseltilerdeki Fenotipik Esnekliğinin Karşılaştırılması, Ordu Üniversitesi, Fen Bilimleri Enstitüsü, Yüksek Lisans Tezi, 45-47s, Ordu.

[13] Meikle, R. D. 1978. Cyclamen L. Davis P. H. ed. 1978. Flora of Turkey and the East Aegean Islands, Edinburgh University Press, Edinburgh, 6, 128-135s.

[14] Ekim, T. 2000. Cyclamen L. Güner A, Özhatay N, Ekim, T., Başer, K. H. C. ed. 2000. Flora of Turkey and the East Aegean Islands, Edinburgh University Press, Edinburgh, 11, 184s.

[15] Öztürk, D. 2012. The International Plant Names Index (IPNI). http://ipni.org/urn:lsid:ipni.org:names:700707 -1, (Erişim Tarihi: 10.06.2019).

[16] Güner, A., Aslan, S. 2012. Türkiye bitkileri listesi:(damarlı bitkiler). Nezahat Gökyiğit Botanik Bahçesi Yayınları. 
[17] Davis, P. H. 1978. Flora of Turkey and the East Aegean Islands. Edinburg University Press, 6, 128-134.

[18] Mathew, B., Özhatay, N. 2001. Türkiye'nin Siklamenleri, Türkiye'de Doğal Olarak Yetişen Siklamen Türlerinin Tanıtım Rehberi. Doğal Hayatı Koruma Derneği, İstanbul, 32s.

[19] Şahin, O., Bürün, B. 2010. Cyclamen alpinum (hort. Dammann ex Sprenger, 1892)'un Morfolojisi, Ekolojisi ve Sitolojisi. Süleyman Demirel Üniversitesi Fen Edebiyat Fakültesi Fen Dergisi, 5(1), 5-15.

[20] Ekim, T., Koyuncu, M., Vural, M., Duman, H., Aytaç, Z., Adıgüzel, N. 2000. Red Data of Turkish Plants. The Council of Protecting the Turkish Nature Press, Ankara, 18, $96 \mathrm{~s}$.

[21] IUCN 2001. IUCN Red List Categories: Version 3.1. IUCN Species Survival Commission. IUCN, Gland, Switzerland and Cambridge, UK.

[22] Wodehouse, R. P. 1935. Pollen Grains. Mc Graw Press, New York, 106-109s.
[23] Çelemli, Ö.G. 2015. Anatomy, Palynology of Endemic Cyclamen pseudoibericum Hildebr. İ Mediterranean Phytogeographic Region of Turkey and Chemical Analysis of Its Tuber Extracts. Hacettepe Journal of Biology and Chemistry, 43(2), 105-113.

[24] Mammadov, R., Dusen, O., Ozay, C. 2016. Autoecological characteristics of Cyclamen mirabile Hildebr.(Primulaceae $)=$ an endemic species of Turkey. Resource Ecology, 4(1), 1-9.

[25] Dusen, O. D., Gurcan, B., Mammadov, R. 2014. Morphology, Anatomy and Palynology of endemic Cyclamen mirabile hildebr. (Primulaceae) in South-West Turkey. Bangladesh Journal of Botany, 43(3), 243-247.

[26] Özbucak, T. B., Polat, G., Akçın Ö. E., Kutbay, H. G. 2017. The effects of elevation on the morphoanatomical and ecological traits in Cyclamen coum subsp. coum Mill. populations in the central black sea region of Turkey in contrasting habitats. Polish Journal of Ecology, 65(2), 211-227. 